\title{
Complementary Feeding Practices And Its Economic And Social Impact: A Cross Sectional Hospital Based Study
}

\author{
Swarup Kumar Bisoi, Mamata Devi Mohanty, Dillip Kumar Dash and Shatabdi Giri
}

Department of Paediatrics, IMS and SUM Hospital, Bhubaneswar, Odisha, India

\author{
Correspondence: \\ Dr Swarup Kumar Bisoi \\ Associate Professor \\ Department of Pediatrics, \\ IMS and SUM Hospital, \\ Bhubaneswar,Odisha, India \\ E-mail: drswarup@outlook.com
}

DOI:10.3126/jnps.v39i1.26473

Submitted on: 2019-11-26

Accepted on: 2020-03-15

Acknowledgements: None

Funding: Nil

Conflict of Interest: None declared

Permission form IRB: Not submitted

To cite this article: Bisoi SK, Mohanty MD, Dash DK, Giri S. Complementary feeding practices and its economic and social impact: A cross sectional hospital based study. J Nepal Paediatr Soc. 2018;39(1):22-8.

\section{ABSTRACT}

Introduction: According to NHFS-4 data, around 38\% of under-five Indian children are malnourished and stunted. In addition to poor socio-economic status, faulty complementary feeding practice is a major contributor to this. The objective of this study is to know the prevailing complementary feeding practices in our area, the most common food type preferred for introduction during initiation of complementary feeds, knowledge of the mother and their family members regarding complementary feeding, the factors influencing in decision making and its financial burden on the family.

Methods: This hospital based cross-sectional study was conducted in a private Medical College in Bhubaneswar, Odisha, India. 256 mothers of infants between six months to two years attending Paediatric OPD from December 2018 to June 2019 were selected by random sampling technique. Data were collected using a structured questionnaire.

Results: Out of the total 256 subjects interviewed, 134 (76.13\%) out of 176 families belonging to lower income group preferred commercially available processed food over home food as the initial weaning food as compared to $32(40 \%)$ out of 80 of the high income group preferring the same. The lower income group spent $22.3 \%$ of the total family income on commercial preparations to feed their infants in the age group six to 12 months. Whereas high income group families spend an average of $14.3 \%$ of family income on baby food products in the same age group. Despite being in regular contact with the local physician, in $85 \%$ of the total visits to the doctor, the opportunity wasn't utilised to counsel the family member about complementary feeding practices.

Conclusions: Commercial preparations are the primary preferred weaning food. The dietary diversity of complementary food is very poor, thus affecting growth and development. The false perception that commercial preparations are critical to child growth and development is overburdening the family finances.

Key words: complementary feeding; commercial processed cereals; income group; mother education

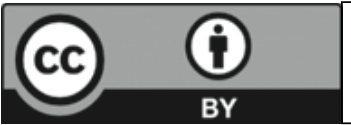

This work is licensed under creative common attribution 3.0 license 


\section{INTRODUCTION}

Infant and young child feeding practices directly affect the nutritional status of children under two years of age and ultimately impact child survival. Improving infant and young child feeding practices in children zero to 23 months of age is therefore critical to improved nutrition, health and development of children. ${ }^{1,2}$ Evidence indicates that inappropriate complementary feeding practices such as untimely introduction of complementary food, improper feeding frequency and low dietary diversity of food have numerous negative effects on children's health. ${ }^{3}$ In India, 38\% of children under age five years are stunted. This is a sign of chronic undernutrition. Twenty-one percent of children under age five years are wasted, which is a sign of acute undernutrition, while $36 \%$ of children under age five years are underweight. ${ }^{4}$ Twenty percent of breastfed children had an adequately diverse diet since they had been given foods from the appropriate number of food groups, while $31 \%$ had been fed the minimum number of times appropriate for their age. ${ }^{4}$ The feeding practices of only $9 \%$ of breast fed children age between six to 23 months, meet the minimum standards for all IYCF (Infant and Young Child Feeding) feeding practices. ${ }^{4}$ Appropriate complementary feeding depends on appropriate information and support from the family, community and healthcare system. The incidence of malnutrition rises sharply during the period from six to 18 months of age in most countries, and the deficits acquired at this age are difficult to compensate for later in childhood. The incidence of malnutrition rising after six months of age indicates the importance of appropriate complementary feeding in future growth of the child. ${ }^{5}$ Inappropriate feeding practices and their consequences are major obstacles to sustainable socioeconomic development and poverty reduction. Governments will be unsuccessful in their efforts to accelerate economic development in any significant long-term sense until optimal child growth and development, especially through appropriate feeding practices, are ensured. ${ }^{6}$ In our ward we observed that most families of the admitted infants were giving commercially available processed cereals along with formula milk as the main complementary food. Their perception was formula milk is an integral part of complementary food along with processed cereals. Very few families were giving home based food like rice, wheat and dal etc. They believed that rice, wheat (chapati) cannot be digested by the baby between six to 12 months, so need to be given after one year of age.

Inadequate knowledge about appropriate food and feeding practices is often a greater determinant of malnutrition than the lack of food. In 2003, Piwoz et al. suggested that globally, complementary feeding has not received adequate attention with regard to infant and young child feeding. Often, complementary feeding was not sufficiently addressed and the main objective has been the promotion, protection and support of breastfeeding. ${ }^{7}$ A focus on Infant and Young Child Feeding (IYCF) is second to management of malnutrition in terms of numbers of lives saved. ${ }^{8}$ Older infants from six months are most vulnerable to malnutrition and growth faltering during the transition period from a milk diet to a diet that includes complementary food. ${ }^{9}$

\section{METHODS}

This hospital based cross-sectional study was conducted in Department of Paediatrics of a tertiary care teaching hospital in Bhubaneswar, Odisha, India between December 2018 to June 2019. Assuming 20\% of breast fed babies (Six months to two years) are given food with adequate dietary diversity ${ }^{4}$ and considering confidence level of $95 \%$, the desired sample size was calculated to be 246 using Open Epi sample size calculator. A total of 256 subjects were enrolled as study participants in this study. Mothers of babies age between six months to two years who visited the our OPD days (Monday) during the study period were informed about the study and asked to participate. Among them a total of 256 eligible mothers who gave their consent were included in the study. The age group of study subjects was selected based on WHO recommendation on complementary feeding. ${ }^{5}$ Babies requiring hospitalisation and those families who refused to participate in the study were excluded. Data were collected by the authors using a structured questionnaire administered to the mothers. The questionnaire consisted of 42 information. It elicited information about 
demographic profile, knowledge and practice of complementary feeding and the factors influencing it, including the role the healthcare provider in counselling regarding complementary feeding. The questionnaire was pretested and was revised to enhance its clarity and comprehension. Detailed anthropometry was done and data on weight and length were used for calculation of nutritional status: weight-for-age, length-for-age and weightfor-length, expressed in standard deviation (SD) units (z-scores) as per the child growth standards of WHO. ${ }^{10}$ Economic condition was categorised as per the RRY(Rajiv Gandhi Rin Yojana), Government of India, as it was easy to reproduce and comprehend. This takes family income into account to classify economic status. It is used by Government of India in various social welfare programs. According to RRY households having an average annual income up to Rupees two lakhs are considered low income group and those above two lakhs higher income group. Percentage was calculated and univariate analysis of the data was done where considered necessary using IBM SPSS Chicago version 20. P value $<0.05$ was considered significant.

\section{RESULTS}

The demographic data of the study population is depicted in table 1 . Of the 256 mothers interviewed, $176(68.8 \%)$ belonged to lower and 80 (31.2\%) to higher economic group. $222(86.7 \%)$ mothers were home makers whereas 34 (13.3\%) were working mothers. $122(47.7 \%)$ children were between six to 12 months, $76(29.7 \%)$ between 13 to 18 months and $58(22.6 \%)$ were between 19 to 24 months. $152(59.4 \%)$ were males whereas 104 $(40.6 \%)$ were females. $88(34.4 \%)$ of the mothers lived in joint families and $168(65.6 \%)$ in nuclear families. Out of the 256 families interviewed 105 (41\%) and 151 (59\%) were from rural and urban areas respectively. $170(66.4 \%)$ were first order and $86(31.2 \%)$ second order child. Considering the mothers formal education, $16(6.3 \%)$ had not attended any school, 46 (18\%) had education up to primary school, $126(49.2 \%)$ high school, 42 $(16.4 \%)$ were graduates and $26(10.1 \%)$ post graduates.

In the present study $79 \%$ mothers started complementary feeding at the recommended age of
Table 1. Social and demographic characteristics of study population

\begin{tabular}{|c|c|c|}
\hline \multicolumn{3}{|c|}{ Social and demographic factors } \\
\hline Characteristics & Number & Percentage $(\%)$ \\
\hline \multicolumn{3}{|l|}{ Age of children } \\
\hline $6 \mathrm{mo}-12 \mathrm{mo}$ & 122 & 47.7 \\
\hline $13 \mathrm{mo}-18 \mathrm{mo}$ & 76 & 29.7 \\
\hline $19 \mathrm{mo}-24 \mathrm{mo}$ & 58 & 22.6 \\
\hline \multicolumn{3}{|l|}{ Gender } \\
\hline Males & 152 & 59.4 \\
\hline Females & 104 & $40 / 6$ \\
\hline \multicolumn{3}{|l|}{ Family Type } \\
\hline Joint & 88 & 34.4 \\
\hline Nuclear & 168 & 65.6 \\
\hline \multicolumn{3}{|l|}{ Place Of Living } \\
\hline Rural & 105 & 41 \\
\hline Urban & 151 & 59 \\
\hline \multicolumn{3}{|l|}{ Mother's education } \\
\hline Illiterate & 16 & 6.3 \\
\hline Primary school & 46 & 18 \\
\hline High school & 126 & 49.2 \\
\hline Graduate & 42 & 16.4 \\
\hline Post Graduate & 26 & 10.1 \\
\hline \multicolumn{3}{|l|}{ Mother's occupation } \\
\hline Home maker & 222 & 86.7 \\
\hline Working & 34 & 13.3 \\
\hline \multicolumn{3}{|l|}{ Economic status } \\
\hline Lower & 176 & 68.8 \\
\hline Upper & 80 & 31.2 \\
\hline \multicolumn{3}{|l|}{ Order Of child } \\
\hline First & 170 & 66.4 \\
\hline Second & 86 & 33.6 \\
\hline
\end{tabular}

six months, $10 \%$ at seven to eight months and $9 \%$ between four to five months and 3\% between three to four months (Figure 1).

The most preferred type of food for initiating complementary feeding was the commercially available processed cereals along with boiled vegetables $(76.1 \%), 17.6 \%$ preferred home based food (supernatant liquid of cooked dal) along with commercially available formula milk, $4.3 \%$ added only formula milk along with breast milk as complementary diet and $2 \%$ giving chattua (Powdered flat rice mix), khichdi (rice porridge) etc ( Figure 2).

In descending order of frequency the most preferred complementary food between age six to 


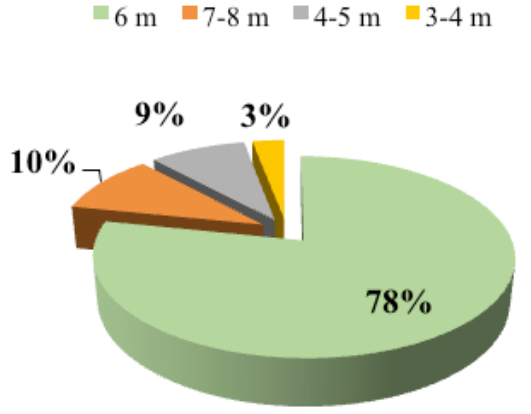

Figure 1. Timing of Complementary Feeding (age in months)

12 months are commercially available processed cereal $>$ supernatant cooked dal $>$ mashed boiled vegetables (papaya, potato, carrot) $>$ rice flake powder $>$ boiled apple. (Fig.3)

The primary source of information regarding what to give in complementary feeds in decreasing order of frequency: Elderly members of family (primarily mother in law) $>$ Neighbours $>$ Local pharmacist $>$ ANM (auxiliary nurse midwife) $>$ Doctor. The local doctors barely have any role in shaping the attitude of the mother $\&$ her family towards appropriate feeding practices.

In this study, $29 \%$ of the children were stunted, $32 \%$ were underweight and $33 \%$ were wasted. Despite the problem of high prevalence under five wasting \& stunting in our children, the opportunity of counselling the mother about complementary feeding during contact with healthcare provider (Doctor) was not utilised in $85 \%$ of times during her visit to the health care facility. In the rest $15 \%$

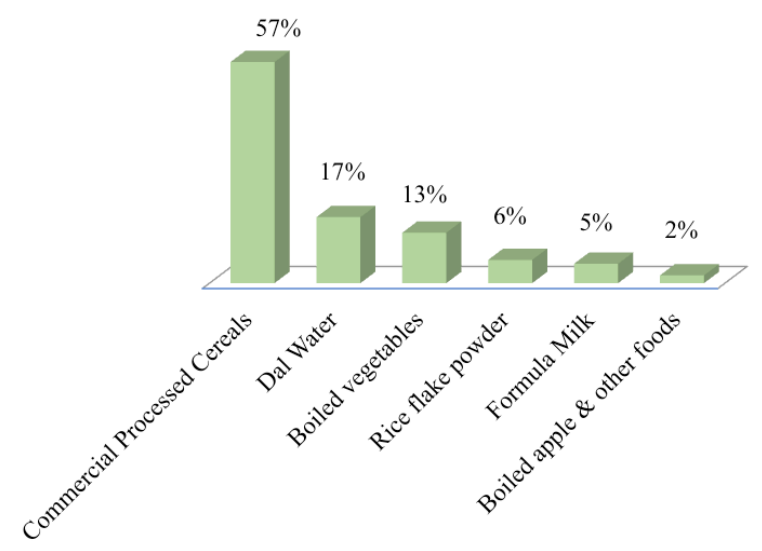

Figure 3. Most preferred food between 6 to 12 months

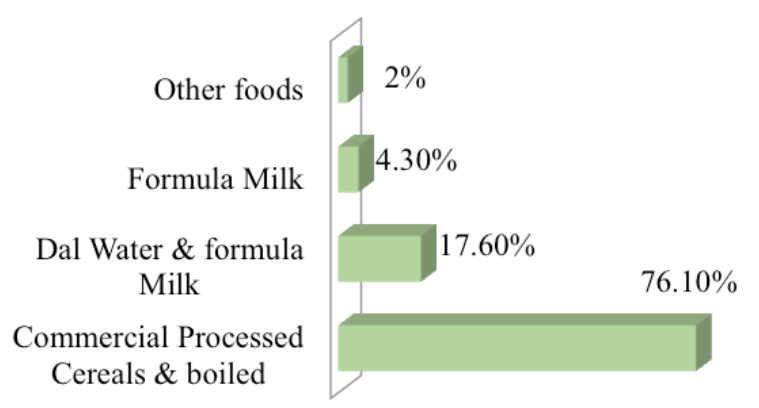

Figure 2. Most preferred initial complementary food

instances despite the doctor's counselling regarding appropriate complementary feeding, it hardly had any effect on the attitude of the mother/family towards complementary feeding.

$72 \%$ of the mothers did not start any rice or wheat based home cooked food until the age of one year due to associated social misconceptions and traditional beliefs. $90 \%$ of the mothers believe their babies cannot digest cereals (Rice) if introduced after six months. Around $83 \%$ did not give appropriate wholesome diet as per Infant \& Young Child Feeding (IYCF) guidelines. $74 \%$ of the mothers believe their baby requires digestive medications if they start home based cereals.

Total Numbers

- Preferring Commercial Preparations 176

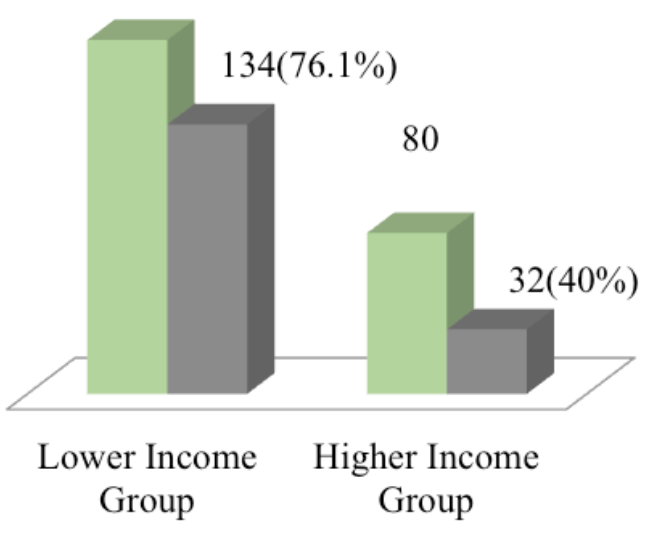

Figure 4. Preference of commercial cereal preparations as per family income group 
Total Number

- Preferring commercial Preparations

151

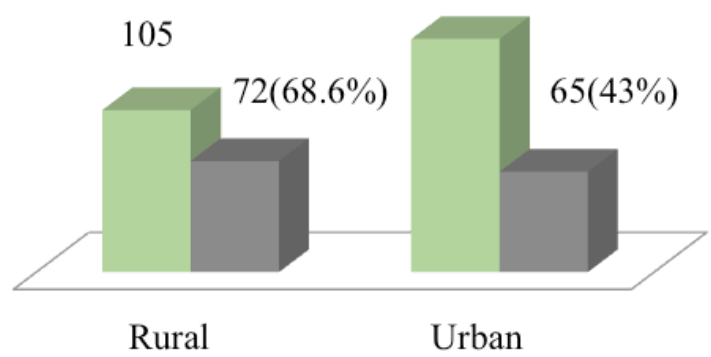

Figure 5. Preference of commercial food preparation as per place of living

The lower income group was more inclined towards commercial preparations for complementary feeds, $134(76.13 \%)$ out of 176 as compared to $32(40 \%)$ out of 80 of the high income group preferring the same $(\mathrm{p}<0.003)$ (Figure 4).

Lesser formal educational status was associated with higher preference for commercial preparation as the primary complementary diet $(p<0.001)$. Mothers residing in rural areas had increased preference for commercial preparation than those in urban areas $(68.6 \%$ versus $43 \%)(p<0.003)$. (Figure 5)

Among the lower income group families, about an average of $22.3 \%$ of the family income is spent on purchasing commercially available baby food products in the age group six to 12 months. Around $10 \%$ of the income is spent on the other needs of the baby. (Fig. 6)

\section{DISCUSSION}

According to UNICEF, the first 1000 days of life, between a woman's pregnancy and her child's second birthday, is a unique period of opportunity when the foundations for optimum health and development across the lifespan are established. The 2015-16 NHFS (National Health and Family Survey), Government of India, the feeding practices of only nine percent of breastfed children age six to 23 months met the minimum standards for all IYCF (Infant and Young Child Feeding)
- Commercial Baby food

- Other needs of baby

(Including Vaccination)

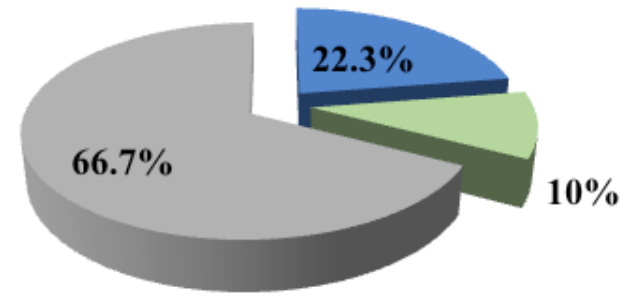

Figure 6. Percentage of family income on baby food and other baby needs (Lower Income Group) between 6-12 months

practices. In one study diversity in the diet of child was significantly associated with better nutritional status, especially height-for-age index in subSaharan children. ${ }^{11}$

In our study $17 \%$ of the breastfed infants between six to 23 months met the minimum standards of IYCF practices, which is better compared to NHFS-4 data. In this study, $29 \%$ of the children were stunted, $32 \%$ were underweight and $33 \%$ were wasted which is similar to national average. In a study by Srivasatava G et al. $29 \%$ of the children were stunted, $32 \%$ were underweight and $33 \%$ were wasted. ${ }^{12}$

In an interventional study of 35 parents in Delhi, only $16.5 \%$ of mothers had started complementary feeding at the recommended time. ${ }^{13}$ A prospective interview study of 200 parents by Aggarwal et al. showed that only $17.5 \%$ of mothers had started complementary feeding at the recommended time. ${ }^{2}$ In our study the initiation of complementary feeding at the recommended age of six months was seen in $79 \%$ of children, which is much better than the mentioned studies. This may be due to the fact that this is a recent study, when the information about breast feeding is much better and more government initiatives to promote breast feeding.

In this study the low income group families and those residing in rural areas are shown to be spending larger proportion of their household income on commercially available food for their 
baby. The increased spending on commercial preparation is significantly associated with less formal education in mothers of low income group and rural areas. There is no other similar type of study for comparison but a study on infant feeding practices in rural Bangladesh by Owais et al. did not find an association between maternal literacy and receipt of minimally acceptable diet at infant age nine months. ${ }^{14}$ According to a study done in Sudan, low parental education is associated with high prevalence of nutritional anaemia and malnutrition. ${ }^{15}$

Significantly less involvement of local health care workers (doctors in particular) in counselling for appropriate complementary feeding to mothers is adding to the problem. Mistry S K et al. found nutritional counselling had a positive role on increasing some of the optimal IYCF practices, which might have resulted in significant reduction in stunting prevalence among children. ${ }^{16}$ Studies from Uganda and Cameroon also reported that counselling mothers on child feeding practices is associated with over all improvement in optimum infant and child feeding practices. ${ }^{17,18}$

In this study the expenditure on commercial preparation is high but due to associated poor dietary diversity and unsustainability due to the expense involved, is responsible for malnutrition in long term. This unnecessary expenditure on commercial preparations can be avoided and the nutritional needs of the babies can be easily addressed with locally available foods, if the families are properly counselled about the importance of dietary diversity in complementary feeding.

Early introduction of more flavourful, rich and sweetened processed cereal preparations is adversely affecting the acceptance of other home based food when introduced at a later age. In most of the times despite coming in contact with health professionals in particular doctors, the opportunity was not utilised to counsel regarding appropriate feeding practices. There may be time constraint on the part of the doctor but this may be very crucial in ensuring the health and wellbeing of our future generation.

\section{CONCLUSIONS}

There is a strong belief on the part of parents that commercial preparations are superior to home based food for their baby. The high cost of commercial preparations make it unsustainable. The dependence on commercial preparations is a hinderance to dietary diversity in complementary feeding. In rural areas and families of lower economic group, the use of processed cereals and formula milk is much higher compared to that in urban areas and families with higher income. Appropriate measures need to be taken at all levels, from government to individuals; particularly health care providers to use all the available opportunities to address the issue of nutrition in children for securing the health of our future generation.

The results obtained may not truly reflect the complementary feeding practices in general population because of the cross sectional study design, institution based study and small sample size. Large scale community based studies are required to find out more appropriate statistical results.

\section{REFERENCES}

1. WHO, Indicators for assessing infant and young child feeding practices : conclusions of a consensus meeting held 6-8 November 2007 in Washington D.C., USA. Part 1 Definitions. https://apps.who.int/iris/bitstream/handle/ 10665/43895/9789241596664_eng.pdf;sequence=1

2. Aggarwal A, Verma S, Faridi MMA, Dayachand. Complementaryfeeding - reasons for inappropriateness in timing,quantity and consistency. Ind J Pediatr. 2008;75(1):49-53. DOI: 10.1007/s12098-008-0006-

3. Saha KK, Frongillo EA, Alam DS, Arifeen SE, Persson LA, Rasmussen KM. Appropriate infant feeding practices result in better growth of infants and young children in rural Bangladesh. Am J Clin Nutr. 2008;87(6):1852-9. DOI :10.1093/ajcn/87.6.1852 
4. International Institute for Population Sciences (IIPS) and ICF. 2017.National Family Health Survey (NFHS-4), 2015-16: India. Mumbai: IIPS.Chapter 10.2.4, Complementary Feeding, pp- 292-296. Available from: http://rchiips.org/nfhs/NFHS-4Reports/ India.pdf

5. Complementary feeding: report of the global consultation, and summary of guiding principles for complementary feeding of the breastfed child. Geneva, 10-13 December 2001. Available from: https://www.who.int/nutrition/publications/ Complementary_Feeding.pdf

6. WHO. Global strategy for infant and young child feeding. WHA55/2002/REC/1 Annex 2 or Geneva: World Health Organisation, 2002. Available from: https://apps.who.int/gb/archive/pdf_files/WHA55/ea5515.pdf

7. Piwoz EG, Huffman SL, Quinn VJ. Promotion and advocacy for improved complementary feeding: can we apply the lessons learned from breastfeeding? Food Nutr Bull.2003;24(1):29-44. DOI: 10.1177/156482650302400103.

8. Bhutta ZA, Das JK, Rizvi A, Gaffey MF, Walker N, Horton S, et al. Evidence-based interventions for improvement of maternal and child nutrition: what can be done and at what cost? Lancet. 2013;382(9890):452-77. DOI:10.1016/S0140-6736(13)60996-4

9. Black RE, Allen LH, Bhutta ZA, Caulfield LE, de Onis M, Ezzati M, et al. Maternal and child undernutrition: global and regional exposures and health consequences. Lancet. 2008;371(9608):243-60. DOI: 10.1016/S0140-6736(07)61690-0

10. World Health Organisation. WHO child growth standards. Length-for-age, weight-for-age, weight for-length, weight-for-height and body mass index for age. Methods and development.Department of Nutrition for Health and Development. Geneva: World Health Organisation,2006:50221. Availbale from: http://www.who.int/childgrowth/standards/Technical_report.pdf .

11. Arimond M, Ruel MT. Dietary diversity is associated with child nutritional status: evidence from 11 demographic and health surveys. J Nutr. 2004;134:2579-85. DOI: 10.1093/jn/134.10.2579

12. Srivasatava G, Bhatnagar S, Khan K A. Complementary feeding practices of children (6 months- 23 months) in and around Lucknow, India. Int J Contemp Pediatr. 2018;5(1):114-118. DOI: 10.18203/2349-3291.ijcp20175570.

13. Sethi V, Kashyap S, Seth V. Effect of nutrition education of mothers on infant feeding practices. Indian J Pediatr. 2003; 70:463-466. DOI: 10.1007/bf02723133.

14. Owais A, Kleinbaum DG, Suchdev PS, Faruque A, Das SK, Schwartz B, et al. Household food security and infant feeding practices in rural Bangladesh. Public Health Nutr. 2016;19(10):1875-81. DOI: 10.1017/ S1368980015003195

15. Abdalla MA, Sulieman SA, El-Tinay AH, Khattab AGH. Socio-economic aspects influencing food consumption patterns among children under age of five in rural area of Sudan. Pak J Nutr. 2009;8:653-9. DOI: 10.3923/pjn.2009.653.659

16. Mistry SK, Hossain MB, Arora A. Maternal nutrition counselling is associated with reduced stunting prevalence and improved feeding practices in early childhood: a post-program comparison study. Nutr J. 2019;18:47. DOI: 10.1186/s12937-019-0473-Z

17. Ickes SB, Baguma C, Brahe CA, Myhre JA, Adair LS, Bentley ME, et al. Maternal participation in a nutrition education program in Uganda is associated with improved infant and young child feeding practices and feeding knowledge: a post-program comparison study. BMC Nutr BioMed Central. 2017;3:32. DOI: 10.1186/s40795-017-0140-8.

18. Reinsma K, Nkuoh G, Nshom E. The potential effectiveness of the nutrition improvement program on infant and young child feeding and nutritional status in the northwest and southwest regions of Cameroon, Central Africa. BMC Health Serv Res. 2016;16:1-9. DOI: 10.1186/s12913-016-1899-z. 